\title{
A INCOMPLETUDE NA CRIAÇÃO FRAGMENTÁRIA DO ESPETÁCULO PRAZER DA CIA. LUNA LUNERA EM RELAÇÃO COM CLARICE LISPECTOR
}

\author{
Danilo França do Nascimento \\ Mestre em Estudos da Linguagem pelo Centro de Educação Tecnológica de Minas Gerais \\ danilofn@gmail.com
}

Este artigo analisa a dramaturgia fragmentária do espetáculo teatral Prazer, da Cia. Luna Lunera, em relação com a literatura de Clarice Lispector, estando ambos objetos de estudo em um permanente estado de incompletude. Entende-se aqui que esta característica fragmentária do espetáculo se aproxima do conceito de Teatro Pós-dramático formulado por Hans-Thies Lehmann, e do conceito de Teatro Performativo formulado por Josette Féral. São realizados também estudos sobre características de narrativa fragmentária e descontínua no livro Uma aprendizagem ou o livro dos prazeres de Clarice Lispector, relacionando-as com o espetáculo Prazer.

Palavras-chave

Teatro. Literatura. Cia. Luna Lunera. Fragmentação. Incompletude. Teatro Pós-Dramático. Teatro Performativo.
This paper analyzes the fragmentary dramaturgy of theatrical spectacle Prazer, by Cia. Luna Lunera, in relation to the literature of Clarice Lispector, which the both objects of study are in a permanent state of incompleteness. It is understood here that this fragmentary character of the spectacle approaches the concept of Postdramatic Theater formulated by Hans-Thies Lehmann, and the concept of Performative Theatre formulated by Josette Féral. Also, there are studies on characteristics of fragmentary and discontinuous narrative in the book Uma aprendizagem ou o livro dos prazeres by Clarice Lispector, relating it to the spectacle Prazer.

Keywords

Theater. Literature. Cia. Luna Lunera. Fragmentation. Incompleteness. Postdramatic Theater. Performative Theater. 
A Luna Lunera é uma Companhia de Teatro formada em Belo Horizonte (MG) por alunos do Curso de Teatro do Centro de Formação Artística do Palácio das Artes (CEFAR). A Companhia é considerada como uma das principais referências do teatro contemporâneo em Minas Gerais, devido ao seu processo criativo investigativo, tendo como foco o trabalho dos atores-criadores. Os lunos (como são conhecidos os integrantes da Cia. Luna Lunera) já montaram os seguintes espetáculos: Fuleirices em fuleiró (2000), Perdoa-me por me traíres (2001), Nesta data querida (2003), Não desperdice sua única vida ou... (2005), Aqueles dois (2007), Cortiços (2008), e Prazer (2012).

No ano de 2011, após um processo de avaliação do que foi realizado nos últimos dez anos da Cia. Luna Lunera, os lunos decidiram montar um novo espetáculo, com o mesmo tipo de processo criativo que já haviam experimentado anteriormente, sobretudo em Aqueles dois. Esse processo, realizado com base no Processo Colaborativo ${ }^{1}$, refere-se ao trabalho de direção e dramaturgia compartilhadas, quando cada ator-codiretor desenvolve o seu próprio projeto de direção com os demais. Foi a partir disso que surgiu a ideia para a montagem de Prazer, que contou com atuação e codireção de Cláudio Dias, Isabela Paes, Marcelo Souza e Silva, Odilon Esteves, e a codireção de Zé Walter Albinati. O espetáculo também contou com a colaboração de artistas convidados, a saber: o dramaturgo Jô Bilac, o videoartista Éder Santos, a atriz Roberta Carreri do Odin

\footnotetext{
1 Segundo Luís Alberto Abreu e Adélia Nicolete (2009), o Processo Colaborativo se refere a diversos tipos de processos de criação teatral da contemporaneidade, quando todos os artistas de uma companhia teatral se integram para uma montagem cênica sem qualquer tipo de hierarquização (direção, texto, interpretação ou outros). O Teatro da Vertigem (SP), com direção de Antônio Araújo, foi o pioneiro desse tipo de Criação Coletiva.
}

Teatret, e o coreógrafo Mário Nascimento.

No projeto artístico para a montagem de Prazer, os lunos apontam como motivações iniciais as muitas colaborações que tiveram acerca das apreciações do público e de parceiros. A partir desses diversos encontros, os artistas da Cia. Luna Lunera conceberam uma questão que serviu como fonte de inspiração para a pesquisa do novo espetáculo: "como o ser humano, diante de sua fragilidade e incompletude, pode romper com o lugar idealizado de perfeição e felicidade para trilhar um caminho de reflexão, transformação e busca de sua essência?" (Cia. Luna Lunera, 2011, s.p). Com base nesse questionamento latente, os lunos tiveram inicialmente como fonte de inspiração os textos de Clarice Lispector, sobretudo o romance Uma aprendizagem ou o livro dos prazeres. Ao longo do processo, por conseguinte, os atores tiveram a liberdade de percorrer a vida e obra da escritora de acordo com suas próprias sensibilidades, além de ter sido igualmente livre o uso de diversos outros materiais em prol da criação do espetáculo.

O espetáculo Prazer mostra a história de quatro amigos (Camilo, Isadora, Marcos, Ozório) que se reencontram em um país estrangeiro, sem defini-lo exatamente. Eles se veem envoltos em momentos distintos um do outro, porém no decorrer do espetáculo torna-se evidente que eles estão vivenciando dilemas e angústias semelhantes em suas vidas. Apesar disso, os quatro amigos têm a coragem de procurar pelo prazer de viver. O apesar de revela-se o mote desses quatro seres em processo (constante formação).

Do mesmo modo, o livro Uma aprendizagem conta uma história simples, porém potente. Clarice Lispector escreveu nesse livro a procura individual e compartilhada da aprendi- 
zagem entre duas pessoas: Lóri e Ulisses. Ambos estão vivendo momentos diferentes um do outro, e por isso mesmo que recebem e doam constantemente entre si. Lóri é uma professora de educação básica, Ulisses é um professor universitário de Filosofia. Ela se encontra fechada ao mundo, e se vê ansiosa por isso. Ele não tem muito mais o que provar a ninguém, mas deseja aprender. Ambos estão à procura de algo, ainda que não saibam exatamente do que se trata. No livro, Lóri e Ulisses se completam sem se fechar, cada um a seu tempo, pois estão em processo.

Diante das múltiplas possibilidades de análises sobre o espetáculo Prazer, uma característica da dramaturgia se mostrou pertinente para um estudo mais aprofundado, no que tange à história não linear do espetáculo. Trata-se de uma dramaturgia fragmentária, fazendo com que o espectador se torne o responsável por, aos poucos, captar o que mais lhe motiva para que possa criar um sentido próprio. Essa característica perpassa toda a obra, mas também é possível encontrar características fragmentárias na dramaturgia de Prazer em momentos específicos como no seu início, quando os quatro personagens - após o momento em que escrevem nas paredes, compondo o cenário -, sentam-se em uma mesa imaginária, em roda. Após um breve momento de silêncio, Isadora é a primeira a falar no espetáculo, sem nenhum tipo de apresentação ao espectador, além dos escritos soltos nas paredes do cenário. Em seguida, os outros três personagens continuam com os mesmos tipos de frases soltas, desconexas, fragmentárias:

ISADORA: Eu embaixo da cachoeira, sentindo a água bater forte. Mas eu era pequena.

MARCOS: Um bando de vagalumes que eu vi em uma mata, numa noite de réveillon. Parecia um céu estrelado. OZÓRIO: Um parto. Um parto que eu presenciei, no estágio ainda, em que a mãe, quando a menininha nasceu, começou a cantar para a filha. João e Maria, do Chico Buarque. Foi lindo, lindo.

[...]

CAMILO: O desfile das campeãs das escolas de samba do Rio de Janeiro, a multidão subindo no carro alegórico para arrancar o plástico preto que cobria o Cristo Redentor do Joãozinho Trinta, que tinha sido proibido no desfile. Nossa! Foi de arrepiar! (Prazer, 2013, 0:01:15).

Logo mais, Isadora revela do que se tratam essas falas iniciais. Referem-se a um tipo de inventário imaterial, assim como um antigo amigo de Isadora fez ao saber de seu estado terminal, quando listou por escrito diversos momentos que marcaram a sua vida para deixar para quem mais ama. Essa cena se inicia em um tempo indeterminado, que também pode ser entendida como o final do espetáculo, quando os quatro amigos já passaram por todo um processo de descobertas sobre o prazer inerente ao próprio ato de viver, e o revelam coletivamente, instigados pela história de Isadora sobre o inventário imaterial. Vale observar que em Uma aprendizagem também há essa característica de se iniciar em um tempo indefinido, sendo possível essa interpretação devido à opção por Clarice Lispector de começar o seu livro com uma vírgula: "[...] estando tão ocupada, viera das compras de casa que a empregada fizera às pressas porque cada vez mais matava serviço [...]" (Lispector, 1998, p. 13).

Após a cena inicial do inventário imaterial, acontece uma forte ruptura em Prazer: há um intenso som de uma das músicas do espetáculo citado pelos personagens, Fuerza bruta, e projeção de frases diversas nas paredes do 
cenário. Concomitante a esse momento do espetáculo, há um caos em que são realizadas leituras aleatórias dos textos nas paredes, falas de um comissário de bordo, uma palestra de um médico com tradução para o francês, trocas de e-mails, tudo realizado por meio de frases soltas e desconexas. Nesta parte já é possível vislumbrar a profissão, a angústia e a coragem de cada um dos quatro personagens e as possíveis relações entre eles, que já começam a ter os seus nomes definidos: Camilo, Isadora, Marcos e Ozório.

Depois das apresentações, as cenas seguintes parecem possuir uma certa linearidade de sentido e tempo. Entretanto, diversos elementos fragmentários se mostram presentes ao longo do espetáculo, tais como os cortes cênicos que podem causar um certo desconforto (crise) ao público. Como exemplo disso, pode-se citar a ruptura que há em meio à cena da preparação do jantar de boas-vindas ao $\mathrm{Ca}$ milo, quando repentinamente Ozório aparece numa ligação de telefone com o seu irmão no Brasil. Após essa cena, subitamente Isadora aparece se olhando ao espelho, com indagações acerca de aparências, sendo interrompida por Camilo ao fazer uma pergunta retórica: "será que ele [o pavão] tem consciência de que se exibe?". Em seguida, outro corte: Marcos conversa a língua inventada com seu cachorro Ulisses, pensando em maneiras para se livrar dele. Após essas rupturas, o espetáculo retorna ao momento de encontro dos quatro amigos, em que se presenteiam como em um ritual antigo que parece terem estabelecido desde quando moravam no Brasil.

Diante dessa análise preliminar, pode-se entender que a característica fragmentária em Prazer se aproxima do conceito de teatro pós-dramático formulado pelo teatrólogo alemão
Hans-Thies Lehmann (2003). Para se compreender esse conceito, faz-se necessário primeiramente entender o significado do termo drama. Para Lehmann (2003), o drama concerne à relação estabelecida entre as pessoas para que seja possível entender a realidade, a partir de elementos tradicionais do teatro, como o tempo, o espaço e as pessoas. O drama está, em suma, associado intrinsecamente à noção de dialética, um conflito em que há sempre uma progressão, acarretando numa síntese. O teatrólogo esclarece então a quebra que há pelo teatro pós-dramático de elementos convencionais do teatro a partir de um exemplo: o elemento tempo. De acordo com a concepção aristotélica, existe uma unidade de tempo que envolve o espectador ao longo do desenvolvimento do drama. Já no teatro moderno, os autores resolveram mostrar o contrário ao se importarem em expor o que é o tempo, transformando-o em um tema. Por isso que houve uma busca pela autonomia desse elemento no teatro, sendo dramatizado de uma forma própria, não mais dentro de um conceito de unidade do drama.

Nesse aspecto, Lehmann (2003) afirma que o teatro pós-dramático não concerne a uma negação ao teatro, mas sim a uma nova etapa de sua história, devido à utilização de elementos tradicionais da arte dramática, porém a partir de uma perspectiva diferenciada. O teatrólogo vê no teatro pós-dramático uma oportunidade de quebrar o modo tradicional do teatro em mostrar uma história, causando um tipo de perturbação (crise) ao espectador: "essa perturbação se torna possível porque esses vários elementos estão agora dissociados, eles podem ser construídos de outra maneira" (Lehmann, 2003, p. 12). O espectador então se torna também responsável pelo que 
é mostrado numa apresentação, sendo uma parte do espetáculo. O público constrói o que é mostrado à sua maneira, em conjunto com os personagens no palco.

Em Prazer, o cenário não naturalista, o figurino sem unidade - um médico que veste saia, outros dois com roupas de festa, ainda outro vestindo-se todo de branco -, e a projeção gráfica evidenciam um escape à ilusão própria do drama tradicional. Outro traço pós-dramático que pode ser evidenciado em Prazer diz respeito ao tempo e ao espaço que se transmutam constantemente. Conforme mencionado, o espetáculo se inicia em um tempo indeterminado, que pode ser até mesmo entendido como o final, ocorrendo diversas rupturas de tempo ao longo do espetáculo. A respeito dos espaços transmutáveis, ora o palco refere-se à casa de um dos personagens, ora é o topo de um edifício, para depois tornar-se o mar, ou mesmo um ambiente cibernético onde e-mails são lidos e respondidos de uma maneira caótica. Ainda, Lehmann (2007) afirma que no teatro pós-dramático, muitas vezes o trabalho do ator não mais se refere à representação de um papel, mas sim a um tipo de trabalho de performer que oferece a si mesmo (sua própria experiência) para a contemplação do público. Essa característica decerto se relaciona com Prazer, por serem evidentes os traços autobiográficos dos atores no processo criativo.

Vale também ressaltar o que Lehmann (2007) afirma ser um princípio do teatro pós-dramático: a desierarquização dos recursos teatrais. Para o teatrólogo, isso permite que a tradição teatral seja mais uma vez contestada. Por certo, essa característica pode também ser atribuída ao processo criativo de Prazer. Aos moldes do Processo Colaborativo, o espetáculo foi realizado de acordo com uma horizontalização de toda criação cênica, sem que houvesse um recurso mais importante que outro. Em outro sentido, essa desierarquização pode ser notada em Prazer de acordo com a utilização de diversos recursos teatrais que dialogam entre si em igualdade, tendo cada recurso a sua linguagem própria. Exemplos disso podem ser a projeção de grafismos (arte digital) enquanto parte do cenário, a manipulação da luz pelos atores, e os movimentos de teatro-dança. Esses elementos decerto emitem múltiplos sentidos ao espectador, contendo cada recurso uma importância igualitária no espetáculo, constituindo uma potente fonte de signos. Desse modo, de acordo com Lehmann (2007, p. 145), "o espectador do teatro pós-dramático não é impelido a uma imediata assimilação do instante, mas a um dilatório armazenamento das impressões sensíveis com 'atenção flutuante por igual'”.

A dramaturga especializada em Processo Colaborativo, Adélia Nicolete (2012), ao realizar uma crítica do espetáculo Prazer, identifica diversas características que podem ser aqui entendidas como relacionadas ao teatro pós-dramático: "mesmo apresentando uma fábula perfeitamente compreensível e personagens com uma trajetória definida, [...] a predisposição ao relacionamento teatro-música-dança-arte digital amplia e intensifica a busca performativa da equipe e exige a colaboração do espectador" (Nicolete, 2012, s.p). A dramaturga ainda afirma que, embora contenha diversos elementos próprios do drama convencional, Prazer consegue impulsionar sua dramaturgia para mais à frente da forma dramática. Isso ocorre devido à utilização pela Cia. Luna Lunera de recursos que distinguem o teatro contemporâneo, como o hibridismo de linguagens artísticas, dramaturgia fragmen- 
tária, e noções modernas sobre o tempo e o espaço em cena.

Nessa perspectiva, torna-se relevante também considerar os estudos de Josette Féral (2008) a respeito do conceito de teatro performativo. Para a pesquisadora, o teatro de hoje possui diversos elementos ligados aos conceitos de performance e performatividade, no que tange à negação da representação (ilusão cênica) e do textocentrismo, à uma nova receptividade do espectador, ou mesmo às novas percepções da tecnologia em cena. Essas características trazem um novo entendimento da arte teatral na contemporaneidade, podendo ser denominado então como teatro performativo. A pesquisadora defende o uso desse termo em contraposição ao que foi definido por Lehmann com semelhantes aspectos, 0 teatro pós-dramático, por se entender que o teatro atual possui em seu cerne a noção de performatividade.

No teatro performativo, de acordo com Féral (2008, p. 204), “a escrita cênica não é aí mais hierárquica e ordenada; ela é desconstruída e caótica, ela introduz o evento, reconhece o risco. Mais que o teatro dramático, e como a arte da performance, é o processo, ainda mais que produto, que o teatro performativo coloca em cena". Ela ainda afirma que o teatro performativo possui as características de pluralidade, fragmentação (não linearidade), ambiguidade, intertextualidade, entre outras. Torna-se, assim, possível considerar esses aspectos no espetáculo Prazer, tendo em vista sua dramaturgia fragmentária, a intertextualidade com Clarice Lispector, a presença de múltiplos sentidos, e o processo criativo enquanto uma parte fundamental do espetáculo (Processo Colaborativo). Ainda, Féral (2008) afirma que no teatro performativo há um engajamento total do artista, no que se refere a um investimento do próprio artista-performer para a sua arte, sendo então tocado subjetivamente. Pode-se assim considerar que os motes pessoais no processo criativo de Prazer evidenciam esse engajamento total do artista, no que tange à entrega que cada luno teve em todo o processo do espetáculo, com a utilização de experiências pessoais enquanto inspiração criativa.

Não obstante, é necessário esclarecer que este artigo não possui como um dos objetivos classificar o espetáculo como pós-dramático e/ou performativo. A identificação de traços pós-dramáticos/performativos no espetáculo se realizou a fim de procurar por mais relações entre Prazer e o universo clariceano, no que tange ao caráter fragmentário, conforme são abordadas nas páginas seguintes. Inclusive, esta necessidade de classificação não apetecia à Clarice Lispector, a ponto de revelar: "[...] gêneros não me interessam mais. Interessa-me o mistério" (Lispector, 1999, p. 347). Tal classificação também não foi um anseio da Cia. Luna Lunera durante o processo criativo do espetáculo, conforme elucida a atriz-codiretora de Prazer, Isabela Paes (2013), em entrevista a esta pesquisa:

Durante a criação, não queríamos que o espetáculo fosse épico, pois muita gente falava que Aqueles dois era épico dramático, então se criou uma discussão muito grande disso. E desejávamos sair desta discussão. Mas depois relaxamos e foi aí que surgiu: "quero ser feio por mais feio que fosse". Essa foi a grande frase. Porque havia cenas que eram mais próximas de uma estética de novela, havia cenas que eram profundamente ligadas numa partitura corporal muito precisa, outras que vinham muito do Contato Improvisação, outras que eram inclassificáveis, que não sabíamos o que eram. Isso tudo vai acontecendo junto dentro da sala de ensaio. Havia 
momentos que ficávamos com medo: "nossa, será que isso não vai dar num Frankenstein danado?". Muito angustiante um processo como este, pois você não sabe aonde vai dar (Paes, 2013, s.p).

Como se pode perceber no relato da atriz, a criação de Prazer transcorreu em fragmentos, sendo então evidente que esta característica do espetáculo se refere a um resultado de seu processo. Outro ator-codiretor de Prazer, Marcelo Souza e Silva (2014), também explicita sobre este caráter fragmentário e caótico na criação do espetáculo. Ele afirma que as primeiras semanas do processo de Prazer decorreram de uma maneira muito ampla, por ainda não terem especificado um tema, um texto-base ou mesmo personagens para se ter como referências de criação. Como exemplo, o ator cita o início do processo, quando foi trabalhada numa semana a preparação corporal dos atores, sem ainda ter uma ideia de como entraria no espetáculo, pois não sabiam especificamente do que o mesmo se tratava. Em outra semana foram trabalhados na sala de ensaio os presentes, sem uma contextualização, somente as ações de dar e receber presentes um ao outro. Esses materiais cênicos criados em fragmentos, ainda descontextualizados, somente começaram a ser estruturados a partir do momento em que os lunos definiram o tema e os personagens do espetáculo. Desse modo, de acordo com o desenvolvimento do processo criativo, os atores-codiretores resgatavam as cenas criadas inicialmente que não tinham um espaço ainda definido no espetáculo, resultando assim no caráter fragmentário que se pode observar em Prazer.

Outro evidente exemplo desta criação fragmentária no espetáculo foi revelado a esta pesquisa pelo ator-codiretor Odilon Esteves
(2014), ao afirmar que houve uma modificação em todo o roteiro dramatúrgico de Prazer quando faltava apenas uma semana para a estreia, que ocorreu numa sexta-feira em São Paulo. No sábado anterior, a Cia. Luna Lunera realizou o último ensaio aberto em Belo Horizonte, quando viu a necessidade de realizar uma série de alterações na ordem das cenas, além da inclusão de outras cenas, a fim de conseguir atingir o espectador da maneira como os atores queriam. Assim, faltando somente uma semana para a estreia, os lunos se viram com um material potente nas mãos, mas que não estava ainda de acordo com o que desejavam. Eles então trabalharam arduamente para conseguir a sutileza pretendida. Esteves (2014) ainda afirma que, mesmo depois da estreia, os atores trabalharam semanalmente para aprimorar cena por cena, trabalho esse que nunca tem uma finalização, mesmo que tais modificações fiquem mais sutis com o passar do tempo.

Nesse viés, torna-se plausível encontrar relações no aspecto fragmentário entre o espetáculo Prazer e a escritura de Clarice Lispector. Tomando como exemplo Água viva, livro publicado por Clarice em 1973, pode-se notar uma narrativa construída de modo não linear, acarretando em silêncios pelo decorrer da obra. Segundo a pesquisadora Janaina Brasil (2006), tais características proporcionam ao leitor exercer uma função muito mais ativa ao preencher, à sua maneira, estes silêncios temáticos e estruturais, tornando-se então um leitor-coautor. Isso é possível devido à linguagem própria estabelecida por Clarice, sobretudo ao se analisar o livro Água viva, quando pode-se perceber uma narrativa contendo confrontos entre o dito e o não dito pela autora. Esta linguagem, em meio a palavras explícitas e ocultas, age como um convite ao leitor para que adentre 
neste jogo da escritura clariceana.

Pode-se observar tal silêncio como multiplicidade de sentidos também em Uma aprendizagem, quando Ulisses ensina à Lóri: "é melhor não falar, não me dizer. Há um grande silêncio dentro de mim. E esse silêncio tem sido a fonte de minhas palavras. $E$ do silêncio tem vindo o que é mais precioso que tudo: o próprio silêncio" (Lispector, 1998, p. 71). Nesse caso, o silêncio se mostra explícito: refere-se a um objetivo de ambos os personagens, a fim de se acharem como sujeitos capazes de se reconhecerem um no outro. Estão os dois aprendendo e ensinando o misterioso prazer de viver, cada um à sua maneira e ao seu tempo. Por isso tamanha é a importância do silêncio nesta obra, pois ele revela muito.

De acordo com Edgar Nolasco (2001), em Uma aprendizagem é possível observar características de narrativa fragmentária e descontínua, assim como na obra Água viva. O pesquisador analisa a escritura de Clarice Lispector a partir de recortes de suas crônicas publicadas no Jornal do Brasil entre os anos de 1967 e 1973. Na escritura de Uma aprendizagem, Clarice se apropria de seus próprios textos-fragmentos (crônicas), entrelaçando-os com a criação de uma história de amor entre Lóri e Ulisses. Tal atividade de reescritura em outro texto pode ser relacionada a uma tradução - multiplicação, disseminação - dos sentidos destes textos-fragmentos dentro de uma mesma linguagem clariceana. Esta característica de criação é chamada pelo pesquisador como uma escritura em palimpsesto, pois, apesar de os textos sobrepostos não terem sido apagados, eles são rasurados durante a apropriação da autora. Por isso que ao ler Uma aprendizagem, o leitor na verdade faz uma releitura, assim como Clarice fez uma reescritura. Nesse aspecto, ambos - autora e leitor - estão empenhados na cocriação da escritura de acordo com os tempos intrínsecos de cada um. Analisando estudos de Nádia Gotlib, Nolasco (2001) ainda observa que este método de escrever por meio da organização de folhas soltas (fragmentos), apetece à Clarice desde que publicou seu primeiro romance, Perto do coração selvagem.

Como exemplo desta criação fragmentária em que Clarice apropria de sua própria escritura, pode-se citar o trecho em que Lóri realiza o autobatismo no mar em Uma aprendizagem (1969) - trecho este que foi traduzido criativamente para o teatro em Prazer -, que foi inicialmente publicado no Jornal do Brasil sob o título Ritual-trecho, em 1968. Três anos mais tarde, o mesmo trecho - com a protagonista denominada apenas como mulher - foi publicado no formato de conto em Felicidade clandestina, sob o título de As águas do mundo. $\mathrm{O}$ trecho ainda é republicado pelo jornal em 1972, sendo posteriormente publicado como um dos textos de Onde estivestes de noite (1974).

Vale ressaltar que não é possível identificar para qual trabalho Clarice escreveu, originalmente, seus textos que foram constantemente reescritos e ressiginificados. Mais relevante é compreender que tais fragmentos clariceanos são como um ambiente propício às entrelinhas, ao se inferir que um fragmento refere-se a um local onde se instala um subtexto, de acordo com Nolasco (2001). O descontínuo e o inacabado propõem ao leitor um infinito recomeço a cada leitura, impregnada de seus sentidos próprios, descentralizando assim os papéis tradicionais de autor/leitor. Trata-se de uma nova modalidade: o leitor-coautor. Tais particularidades, portanto, são um desafio ao leitor-coautor que pode dar aos múltiplos fragmentos 
dos textos clariceanos uma consistência própria. "Parece só restar ao leitor, frente à escritura que tece os diversos saberes ao tecer-se, dando uma visão pluralística do mundo e tendo este como seu reflexo, jogar com a prática escritural [...], para que possa ainda mais pluralizar a linguagem e multiplicar os sentidos" (Nolasco, 2001, p. 96). Esse entendimento condiz com o que Clarice considera ser o papel do leitor, ao afirmar: "o personagem leitor é um personagem curioso, estranho. Ao mesmo tempo que inteiramente individual e com reações próprias, é tão terrivelmente ligado ao escritor que na verdade ele, o leitor, é o escritor" (Lispector, 1999, p. 79). Desse modo, para ler Clarice, o leitor precisa ser, antes de tudo, um escritor que tece ao lado da escritora seus textos de múltiplos sentidos e significados.

Assim como na literatura de Clarice Lispector, em Prazer não é possível saber em definitivo o seu desfecho, sendo portanto incerto o destino dos personagens. É evidente, porém, que tanto nos personagens clariceanos quanto nos de Prazer, há uma busca pela aprendizagem de si mesmos e do prazer de existir. E essa busca permanece para além do desfecho do livro e do espetáculo. Faz-se notável, no espetáculo, uma busca por vivenciarem a condição humana por meio do confronto com a morte, a separação, o desejo, o amor, o ódio, o medo. Esse processo de humanização é realizado pelos personagens de um modo individual para que depois se torne coletivo. Essa busca existencial é evidente em cada confronto/encontro realizado em cena pelos personagens. No entanto, eles não estão no palco para se resolverem - tornarem-se completos -, mas sim para tentarem aprender o prazer de viver em meio à crise: o apesar de.

Com histórias fragmentárias, portanto, tanto a Cia. Luna Lunera em Prazer, quanto Clarice Lispector - cada qual à sua maneira - convidam seu público/leitor a assumir o posto de coautor da história de acordo com as suas próprias vivências, significados e sentimentos. Pode-se ainda relacionar os processos criativos e o caráter fragmentário de Prazer e de Clarice Lispector com a condição humana, vivendo em um mundo incompleto, inacabado, em que o indivíduo se vê perdido de si mesmo. Conforme já mencionado, esta questão da incompletude se fez presente no processo criativo de Prazer, provavelmente devido à fonte existencialista de Clarice Lispector. Pois tal inspiração surgiu em decorrência dos questionamentos dos atores sobre o indivíduo em permanente crise existencial. Uma crise que instiga os criadores, personagens e o público/leitor a se tornarem capazes de uma aprendizagem de si mesmos (e seus prazeres), bem como de se relacionar poeticamente com o mundo.

Referências

ABREU, Luís Alberto; NICOLETE, Adélia. Processo colaborativo. In: GUINSBURG, J.; FARIA, João Roberto; LIMA, Mariângela Alves de. Dicionário do teatro brasileiro: temas, formas e conceitos. 2. ed. São Paulo: Perspectiva, 2009.

BRASIL, Janaina. A inexpressão na obra Água viva de Clarice Lispector. Dissertação de Mestrado. Niterói/RJ: UFF, 2006. 
CIA. LUNA LUNERA. Projeto artístico do espetáculo Prazer. Belo Horizonte: 2011. Texto não publicado.

ESTEVES, Odilon. Entrevista sobre o espetáculo Prazer. Belo Horizonte, 15 ago. 2014. Entrevista concedida ao pesquisador. Texto não publicado.

FÉRAL, Josette. Por uma poética da performatividade: o teatro performativo. Trad. Lígia Borges. In: Sala Preta, São Paulo, v. 8, p. 197-210, 2008.

LEHMANN, Hans-Thies. Teatro pós-dramático e teatro político. Trad. Rachel Imanishi. In: Sala Preta, São Paulo, v. 3, p. 9-19, nov. 2003.

LEHMANN, Hans-Thies. Teatro pós-dramático. Trad. Pedro Süssekind. São Paulo: Cosac Naify, 2007.

LISPECTOR, Clarice. Uma aprendizagem ou o livro dos prazeres. Rio de Janeiro: Rocco, 1998.

LISPECTOR, Clarice. A descoberta do mundo. Rio de Janeiro: Rocco, 1999.

NICOLETE, Adélia. Prazer, do Luna Lunera ou Uma aprendizagem do teatro contemporâneo. In: Papel fere pedra. 2012. Disponível em: $\quad<$ http://papelferepedra.blogspot.com. br/2012/12/prazer-do-luna-lunera-ou-uma. html>. Acesso em: 30 nov. 2013.

NOLASCO, Edgar Cézar. Clarice Lispector: nas entrelinhas da escritura. São Paulo: Annablume, 2001.
PAES, Isabela. Entrevista sobre o espetáculo Prazer. Belo Horizonte, 11 dez. 2013. Entrevista concedida ao pesquisador. Texto não publicado.

PRAZER. Espetáculo teatral gravado em DVD. Concepção e dramaturgia: Cia. Luna Lunera. Atuação e codireção: Cláudio Dias, Isabela Paes, Marcelo Souza e Silva, Odilon Esteves. Codireção: Zé Walter Albinati. Belo Horizonte, dez. 2013. $97 \mathrm{~min}$.

SOUZA E SILVA, Marcelo. Entrevista sobre o espetáculo Prazer. Belo Horizonte, 22 jul. 2014. Entrevista concedida ao pesquisador. Texto não publicado.

Recebido: 28/12/2015 Aprovado: 08/06/2017 